\title{
Patient-perceived health-related quality of life before and after laparoscopic aortobifemoral bypass
}

\author{
Syed SH Kazmi' \\ Anne H Krog ${ }^{1,2}$ \\ Simen T Berge' \\ Jon O Sundhagen' \\ Mehdi Sahba ${ }^{3}$ \\ Ragnhild S Falk ${ }^{4}$ \\ 'Department of Vascular Surgery, \\ Division of Cardiovascular and \\ Pulmonary Diseases, Oslo University \\ Hospital, ${ }^{2}$ nstitute of Clinical \\ Medicine, University of Oslo, Oslo, \\ ${ }^{3}$ Department of Vascular Surgery, \\ Østfold Central Hospital, Kalnes, \\ ${ }^{4}$ Oslo Centre for Biostatistics \\ and Epidemiology (OCBE), Oslo \\ University Hospital, Oslo, Norway
}

This article was published in the following Dove Press journal:

Vascular Health and Risk Management

12 May 2017

Number of times this article has been viewed

Background: In patients operated with laparoscopic aortobifemoral bypass (LABFB) for atherosclerotic obstruction in aortoiliac segment, the main focus of the reports published during the last two decades has been morbidity and mortality. The primary objective of this study was to examine the health-related quality of life (HRQL) in these patients before and after LABFB. Patients and methods: Fifty consecutive patients (27 females) with Trans-Atlantic InterSociety Consensus II, type D lesions were prospectively included. Short-Form 36 (SF-36) questionnaire was used to get information about the HRQL before LABFB and at 1, 3 and 6 months after the operation. Main indication for LABFB was intermittent claudication. Linear mixed-effect models were used to assess changes in HRQL over time. Age, gender, smoking, blood loss, operation time, concomitant operation, the American Society of Anesthesiologists category, length of hospital stay, previous vascular procedures and aorta cross-clamping were used as fixed factors and their impact on the physical components of the SF-36, as well as the summary scores were determined with univariate analysis. Variables with $P<0.2$ were included in the multivariate regression analysis. $P<0.05$ was considered statistically significant.

Results: Statistically significant improvement was found in all SF-36 domains as well as in the summary scores after LABFB compared to the preoperative scores. The improvement in scores was substantial already at 1 month and the effect was maintained at 3 and 6 months survey time points. Concomitant operations had a statistically significant negative impact on the physical components of SF-36. Data completeness of item questionnaires was $93 \%$ in the whole material. Reliability scale and homogeneity estimates for the eight domains had high internal consistency. Conclusion: Patients operated with LABFB for Trans-Atlantic Inter-Society Consensus II, type D lesions have reduced HRQL. LABFB leads to substantial and statistically significant improvement in the patients' HRQL, when examined with SF-36. These results need to be replicated by a randomized clinical trial.

Keywords: quality of life, vascular, laparoscopy, aortoiliac atherosclerosis, aortic surgery, aortobifemoral bypass, laparoscopic vascular surgery

\section{Background}

Laparoscopic aortobifemoral bypass (LABFB) for the treatment of advanced aortoiliac occlusive disease (AIOD) has become an established treatment option in dedicated centers. ${ }^{1}$ Intermittent claudication and reduced walking distance are often the main symptoms in patients with AIOD. ${ }^{2}$ Often the initial treatment, even for the advanced atherosclerotic lesions, is in the form of percutaneous transluminal angioplasty. ${ }^{3}$ However, in case of failure, surgical treatment with an aortobifemoral bypass (ABFB) remains an ultimate treatment option..$^{4-7}$
Correspondence: Syed SH Kazmi Department of Vascular Surgery, Oslo University Hospital, Aker Trondheimsveien 235, 0586 Oslo, Norway Email sshkazmi@gmail.com 
The Health-Related Quality of Life (HRQL) after percutaneous transluminal angioplasty for the treatment of peripheral atherosclerotic disease has been shown to be better than after conventional surgery. ${ }^{8-10}$ Although the patients' own evaluation of changes in health status is an increasingly important factor in the evaluation of a new treatment modality, ${ }^{11}$ the main focus in the published literature about the operative treatment of AIOD with LABFB has been the classical endpoints such as graft patency, morbidity and mortality., ${ }^{4,6,12}$ Little has been written in literature about the HRQL after LABFB.

The main aim of this study was to examine changes in HRQL, before and after LABFB, with the help of Short Form-36 (SF-36). ${ }^{13}$ In particular, we wished to identify the clinical variables that may have impact on the physical health domain of the SF-36 and on the summary scores.

\section{Methods}

Between November 2005 and December 2011, patients with AIOD, classified as Trans-Atlantic Inter-Society Consensus (TASC) II, type D lesions, were treated with LABFB at the Oslo University Hospital and were eligible for inclusion in the study. ${ }^{2}$ The same group of patients also took part in a comparative cohort study for comparison of LABFB and open ABFB (OABFB). ${ }^{1}$ The main indication for surgery was debilitating intermittent claudication defined as maximum pain-free walking distance of $<200 \mathrm{~m}$ (Rutherford's category 3). ${ }^{14}$ Only patients not amenable to or with a previously unsuccessful endovascular treatment were selected for surgery. Patients with previous multiple abdominal surgery were not offered LABFB.

Written informed consent was obtained from all patients before the operation and for taking part in this study. The study was approved by the Regional Committee for Medical and Health Research Ethics North (registration number 2010/1953-1954) and was also registered at ClinicalTrials. gov (NCT01259908).

We utilized the SF-36 Health Survey, Norwegian Version 1.2 to assess the HRQL in all patients in this study. ${ }^{13} \mathrm{SF}-36$ is an extensively used generic HRQL tool. ${ }^{13,15-17}$ SF-36 assesses eight different HRQL domains, including physical functioning (PF), role limitations due to physical problems (RP), bodily pain (BP), general health (GH), vitality (VT), social functioning (SF), role limitations due to emotional problems (RE) and mental health $(\mathrm{MH})$. Scores for each dimension are converted to a scale of $0-100$, where a higher score indicates a better HRQL. Summary score can be analyzed overall or divided into physical component score (PCS) and mental component score
(MCS).$^{18}$ SF-36 is translated into Norwegian language and has been validated for the Norwegian population. ${ }^{19}$ The SF-36 questionnaires were given to the patients before LABFB and postoperatively at 1, 3 and 6 months.

Patients' response to the SF-36 questionnaires was registered in the QualityMetric Health Outcomes Scoring Software 5.0 program. The scoring software was used to calculate the score for each of the eight domains in the SF-36, the PCS and MCS summary scores as well as for calculating divergent validity of the collected data. Descriptive data are presented as frequencies with proportions and as median with interquartile range. Internal consistency of the components of SF-36 domains was assessed using Cronbach's alpha.

Linear mixed-effect models were used to assess changes in HRQL over time. The PF, RP, BP, PCS and MCS were assessed as dependent factors. All models included fixed effect for time as the categorical variable. In addition, the variables age, gender, smoking, blood loss, operation time, concomitant operation, the American Society of Anesthesiologists (ASA) category, length of hospital stay, previous vascular procedure and aorta cross-clamping time were considered for inclusion. Variables with $P<0.2$ in univariate analysis were included as fixed factors in the multivariate model. Then, the least significant variable was excluded, one at a time, until all remaining factors were statistically significant. In all models, a random intercept was included and the covariance structure was specified as first-order autoregressive, that is, correlations between the residuals fall off as the time between the measurements increases. No multicollinearity between the included factors was found. Interaction effects between time and the fixed factors were checked by including product terms, one at a time, into the models. No significant interactions were observed.

$P$-values $<0.05$ were considered statistically significant. We used STATA 14.0 software statistical program (StataCorp LP, College Station, TX, USA).

\section{Results}

Fifty patients with AIOD TASC II, type D lesions were included prospectively. All patients were in Rutherford's category 3, except two patients who were in Rutherford's category 5. All patients, except two with critical limb ischemia, underwent an initial conservative treatment period of at least 3 months, which included instruction about walking exercise and risk factor modification (smoking cessation, antiplatelets, statins, better treatment for diabetes mellitus and hypertension). ${ }^{2}$ Descriptive data are presented in Table 1. 
Table I Clinical characteristics of 50 patients operated with LABFB

\begin{tabular}{ll}
\hline Variables & LABFB, N=50 \\
\hline Age in years & $62(59-67)^{\mathrm{a}}$ \\
Gender: female/male & $23 / 27$ \\
BMI & $24.2(22.8-25.7)^{\mathrm{a}}$ \\
Hypertension & $38(76 \%)$ \\
CHD & $17(34 \%)$ \\
Dyslipidemia & $30(60 \%)$ \\
Diabetes mellitus & $6(12 \%)$ \\
Tobacco use & $37(74 \%)$ \\
ASA category 3 & $36(72 \%)$ \\
COPD & $14(28 \%)$ \\
Prior vascular intervention/operation & $22(44 \%)$ \\
Run-off artery stenosis/occlusion & $21(42 \%)$ \\
Prior laparotomy & $14(28 \%)$ \\
Concomitant operation & $35(70 \%)$ \\
\hline
\end{tabular}

Note: aMedian and interquartile range.

Abbreviations: ASA category 3, the American Society of Anesthesiologists category 3; BMI, body mass index; CHD, coronary heart disease; COPD, chronic obstructive pulmonary disease; LABFB, laparoscopic aortobifemoral bypass.

LABFB was completed in $43(86 \%)$ patients. In seven patients (14\%), the procedure was converted to an OABFB through a midline laparotomy and a transperitoneal approach to the infrarenal aorta. LABFB procedures were performed by a transabdominal, retrocolic and prerenal approach as described by Coggia et al. ${ }^{4}$ Only one (2\%) patient died within 30 days after LABFB. The death was due to an acute myocardial infarction and the patient was in ASA category 3. The conventional results of LABFB in this study have previously been published in a comparative cohort study. ${ }^{1}$

Before operation, $100 \%$ of the cases completed SF-36 questionnaires, and data could be obtained from $98 \%(\mathrm{n}=49)$, $94 \%(n=44)$ and $80 \%(n=40)$ of the patients, respectively, at 1,3 and 6 months postoperatively. Data completeness of the item questionnaires was $93 \%$ in the whole material. Items internal consistency was $97 \%$ and discriminant validity was $98 \%$. Reliability scale and homogeneity estimates for the eight domains showed high Cronbach's alpha for all of them, indicating a high degree of internal consistency (Table 2).

Figure 1 illustrates the observed SF-36 scores by domain at different time points in this study. We found statistically significant improvement in the scores of all SF-36 domains postoperatively, as compared to the preoperative scores. The improvement in postoperative HRQL was substantial already at 1 month, and this effect was maintained and still significant at 3 and 6 months as compared to the baseline.

The PCS summary scores showed significant improvement at all the postoperative survey time points as compared to the preoperative scores, whereas the MCS scores showed improvement only at 6 months (Figure 1).
Table 2 Scale reliability and homogeneity estimates of SF-36 response at all time points (preoperative, I, 3 and 6 months postoperatively) in 50 patients operated with laparoscopic aortobifemoral bypass for TASC II type D lesions

\begin{tabular}{lll}
\hline Scale & Number of items & Cronbach's alpha \\
\hline Physical functioning & 10 & 0.937 \\
Role physical & 4 & 0.897 \\
Bodily pain & 2 & 0.848 \\
General health & 5 & 0.778 \\
Vitality & 4 & 0.867 \\
Social functioning & 2 & 0.867 \\
Role emotional & 3 & 0.857 \\
Mental health & 5 & 0.800 \\
\hline
\end{tabular}

Abbreviations: SF-36, Short-Form 36; TASC, Trans-Atlantic Inter-Society Consensus.

In the mixed-effect models, univariate regression analysis showed statistically significant or a near-borderline significant negative effect of the following variables on one or more of the physical domains of the SF-36: blood loss, concomitant operations, length of hospital stay and ASA category 3. However, despite statistical significance, only concomitant operations had a substantial negative effect on the PF and RP scores ( -10.9 points and -21.6 points, respectively). This negative effect of concomitant operations was also observed in the multivariate regression analysis ( -9.6 points and -20.5 points for PF and RP, respectively; Tables 3-5).

Although blood loss had a statistically significant negative effect on postoperative PF scores, its magnitude was not substantial.

In the multivariate regression analysis, only smokers had substantial and statistically significant higher PF and RF scores ( 8.5 points and 15.6 points, respectively; Tables 3 and 4).

In the multivariate regression analysis of the $\mathrm{BP}$ domain of SF-36, no clinical variables had significant impact on the scores (Table 5).

When studying PCS, a positive impact of smoking and a negative impact of concomitant operation and blood loss were found (Table 6).

In case of MCS, the univariate regression analysis showed that only the length of hospital stay had a statistically significant $(P<0.03)$ negative effect on the score, but its magnitude was not substantial ( -0.3 points change per day; Table 7$)$. This impact of the length of hospital stay maintained its statistical significance $(P<0.046,95 \%$ confidence interval $-0.48,-0.01)$ in the multivariate regression analysis.

\section{Discussion}

Although intermittent claudication is not an immediate limb-threatening condition, impairment in walking ability 

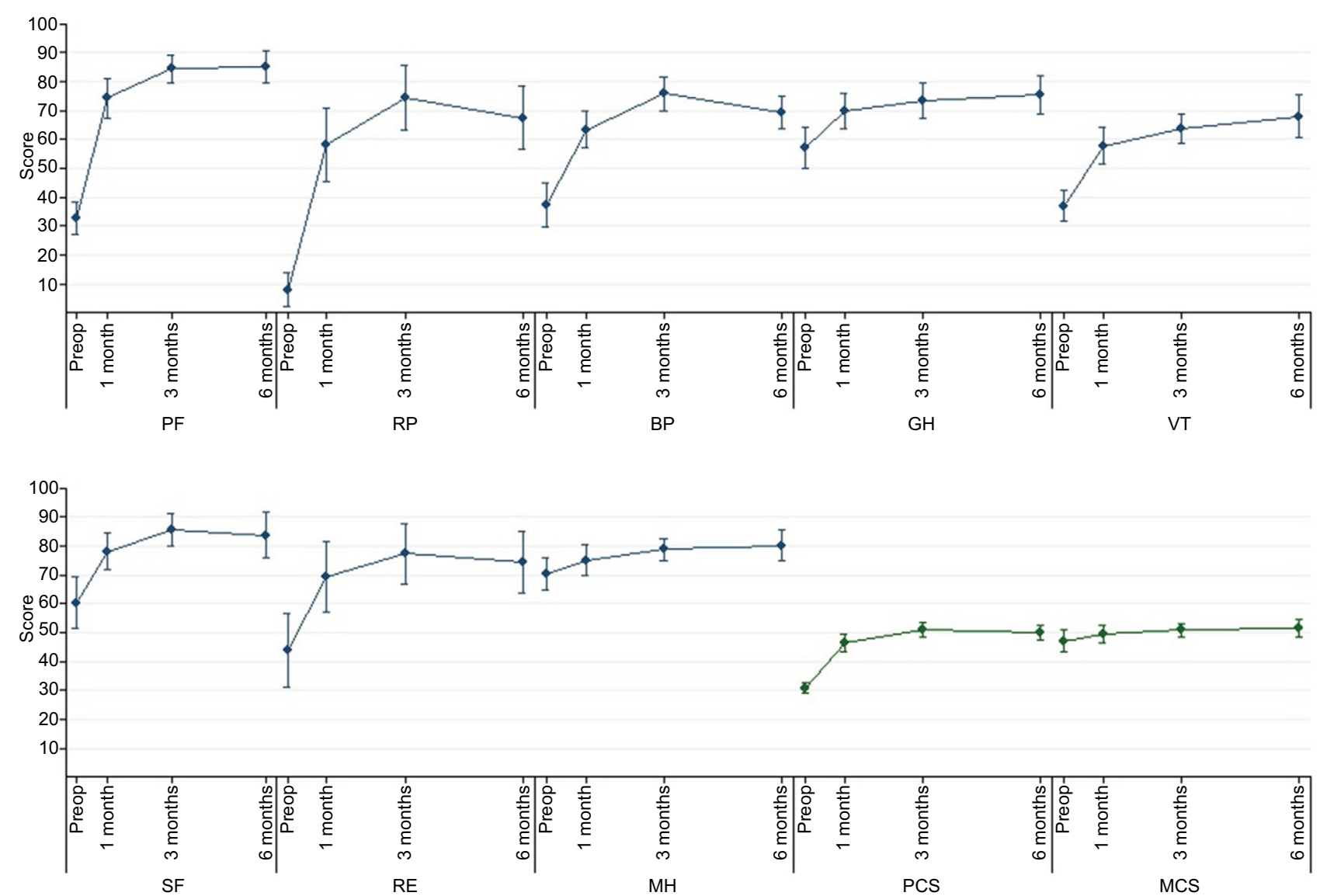

Figure I Changes in the scores (observed mean values) of individual domains in the SF-36, in 50 patients before and after laparoscopic aortobifemoral bypass for the treatment of aortoiliac occlusive disease (Trans Atlantic Inter-Society Consensus II, type D lesions).

Notes: Changes in summary scores PCS and MCS are also illustrated. The vertical bars represent $95 \%$ confidence interval.

Abbreviations: BP, bodily pain; GH, general health; MCS, mental component score; MH, mental health; PF, physical functioning; PCS, physical component score; RP, role limitations due to physical problems; RE, role limitations due to emotional problems; SF, social functioning; SF-36, Short-Form 36; VT, vitality.

Table 3 Results of the linear mixed-effect regression analysis (univariate and multivariate) of the physical component of the SF-36, PF, at I, 3 and 6 months after laparoscopic aortobifemoral bypass of 50 patients for aortoiliac occlusive disease, TASC II, type D lesions

\begin{tabular}{|c|c|c|c|c|c|c|}
\hline \multirow[t]{2}{*}{ Time } & \multicolumn{3}{|l|}{ Univariate } & \multicolumn{3}{|l|}{ Multivariate } \\
\hline & Coefficient & $\begin{array}{l}95 \% \text { Confidence } \\
\text { interval }\end{array}$ & $P$-value & Coefficient & $\begin{array}{l}95 \% \text { Confidence } \\
\text { interval }\end{array}$ & $P$-value \\
\hline Time, preop & Ref & & & Ref & & \\
\hline I month & 41.6 & $35.33,47.82$ & 0.001 & 41.5 & $35.17,47.77$ & 0.001 \\
\hline 3 months & 52.0 & $44.96,58.97$ & 0.001 & 51.9 & $45.01,58.75$ & 0.001 \\
\hline 6 months & 52.6 & $45.14,60.09$ & 0.001 & 52.1 & $44.86,59.38$ & 0.001 \\
\hline Smoking (yes vs no) & 7.5 & $-0.97,15.96$ & 0.082 & 8.1 & $1.12,15.18$ & 0.023 \\
\hline Blood loss (dL) & -0.9 & $-1.35,-0.43$ & 0.001 & -0.8 & $-1.17,-0.32$ & 0.001 \\
\hline Concomitant operation (yes vs no) & -10.9 & $-18.59,-3.20$ & 0.01 & -9.8 & $-16.54,-2.98$ & 0.005 \\
\hline ASA (category 3 vs category I+2) & -6.1 & $-14.2 \mid, 2.03$ & 0.141 & & & \\
\hline Length of hospital stay (days) & -0.5 & $-1.00,-0.05$ & 0.030 & & & \\
\hline Aorta clamping (minutes) & 0.14 & $-0.03,0.31$ & 0.107 & & & \\
\hline Age (years) & -0.2 & $-0.73,0.37$ & 0.516 & & & \\
\hline Gender (male/female) & 0.4 & $-7.25,8.10$ & 0.914 & & & \\
\hline Operation time (minutes) & 0.03 & $-0.10,0.04$ & 0.464 & & & \\
\hline $\begin{array}{l}\text { Prior vascular operation or } \\
\text { intervention }\end{array}$ & 3.5 & $-4.13,11,17$ & 0.367 & & & \\
\hline
\end{tabular}

Abbreviations: ASA, the American Society of Anesthesiologists category; PF, physical functioning; Ref, reference; SF-36, Short Form-36; TASC, Trans-Atlantic Inter-Society Consensus. 
Table 4 Results of the linear mixed-effect regression analysis (univariate and multivariate) of the physical component of the SF-36, role physical, at I, 3 and 6 months after laparoscopic aortobifemoral bypass of 50 patients for aortoiliac occlusive disease, TASC II, type D lesions

\begin{tabular}{|c|c|c|c|c|c|c|}
\hline \multirow[t]{2}{*}{ Time } & \multicolumn{3}{|l|}{ Univariate } & \multicolumn{3}{|l|}{ Multivariate } \\
\hline & Coefficient & $\begin{array}{l}\text { 95\% Confidence } \\
\text { interval }\end{array}$ & $P$-value & Coefficient & $\begin{array}{l}\text { 95\% Confidence } \\
\text { interval }\end{array}$ & $P$-value \\
\hline Time, preop & Ref & & & Ref & & \\
\hline I month & 50.1 & $38.83,61.39$ & 0.001 & 49.9 & $38.64,61.12$ & 0.001 \\
\hline 3 months & 66.65 & $54.60,78.71$ & 0.001 & 66.5 & $54.33,78.75$ & 0.001 \\
\hline 6 months & 59.3 & $46.62,72.10$ & 0.001 & 59.0 & $46.10,71.90$ & 0.001 \\
\hline Smoking (yes vs no) & $|4.3|$ & $-0.10,28.72$ & 0.052 & 15.6 & $3.0 \mathrm{I}, 28.25$ & 0.01 \\
\hline Blood loss (dL) & -1.0 & $-1.79,-0.11$ & 0.027 & & & \\
\hline Concomitant operation (yes vs No) & -21.57 & $-34.37,-8.76$ & 0.001 & -20.5 & $-33.12,-7.88$ & 0.001 \\
\hline ASA (category 3 vs I+2) & -13.8 & $-27.39,-0.11$ & 0.048 & & & \\
\hline Length of hospital stay (days) & -0.4 & $-1.19,0.47$ & 0.390 & & & \\
\hline Aorta clamping (minutes) & 0.1 & $-0.21,0.38$ & 0.576 & & & \\
\hline Age (years) & -0.01 & $-1.0,1,0$ & 0.983 & & & \\
\hline Gender (male/female) & 0.8 & $-12.36,14.00$ & 0.903 & & & \\
\hline Operation time (minutes) & -0.1 & $-0.18,0.06$ & 0.350 & & & \\
\hline Prior vascular operation or intervention & 3.3 & $-9.93,16.48$ & 0.627 & & & \\
\hline
\end{tabular}

Abbreviations: ASA, the American Society of Anesthesiologists category; Ref, reference; SF-36, Short Form-36; TASC, Trans-Atlantic Inter-Society Consensus.

Table 5 Results of the linear mixed-effect regression analysis (univariate and multivariate) of the physical component of the SF-36, bodily pain, at I, 3 and 6 months after laparoscopic aortobifemoral bypass of 50 patients for aortoiliac occlusive disease, TASC II, type D lesions

\begin{tabular}{llll}
\hline Time & Univariate & & \\
\cline { 2 - 4 } & Coefficient & $\mathbf{9 5 \%}$ Confidence interval & P-value \\
\hline Smoking & 3.3 & $-6.72,13.31$ & 0.519 \\
Blood loss (dL) & -0.6 & $-1.18,-0.04$ & 0.035 \\
Concomitant operation (yes vs no) & -6.7 & $-16.11,2.64$ & 0.159 \\
ASA (category 3 vs category I+2) & -1.8 & $-11.40,7.76$ & 0.710 \\
Length of hospital stay (days) & -0.4 & $-0.91,0.20$ & 0.205 \\
Aorta clamping (minutes) & 0.02 & $-0.18,0.21$ & 0.867 \\
Age (years) & 0.3 & $-0.37,0.90$ & 0.417 \\
Gender (male/female) & 2.1 & $-6.75,10.90$ & 0.645 \\
Operation time (minutes) & 0.03 & $-0.05,0.11$ & 0.465 \\
Prior vascular operation or intervention & 4.5 & $-4.32,13.34$ & 0.317 \\
\hline
\end{tabular}

Abbreviations: ASA, the American Society of Anesthesiologists category; SF-36, Short Form-36; TASC, Trans-Atlantic Inter-Society Consensus.

and the associated pain seems to result in a reduction of the patients' physical and mental well-being. This study shows a substantially lower HRQL among the patients with TASC II type D lesions. The main symptom among the patients with this advanced atherosclerotic disease in the aortoiliac segment is intermittent claudication. Patients with peripheral atherosclerotic disease have previously reported lower scores in the pain and physical domains, compared to the healthy controls. ${ }^{16}$ The baseline SF-36 scores in our patient cohort are also consistent with studies regarding the impact of intermittent claudication on the patients' perceived HRQL. ${ }^{10}$ Previously, reduction in the HRQL of patients with intermittent claudication was found to be comparable to that of patients with osteoarthritis or rheumatoid arthritis of the hip or knee joint or of patients with coronary artery disease. . $^{8,20,21}$

Our study shows that the patients have statistically significant improvement in the HRQL, based on the substantial improvement in the postoperative scores for all the SF-36 domains. Since the main symptom among the patients in this study was intermittent claudication which is mainly a physical disability, we were particularly interested in finding the postoperative changes in the physical health domains of the SF-36, namely, PF, RP and BP. In addition, we aimed to estimate the changes in PCS and MCS. We found a substantial improvement in postoperative summary scores compared to the preoperative scores. After LABFB, the improvement in 
Table 6 Results of the linear mixed-effect regression analysis (univariate and multivariate) of PCS at I, 3 and 6 months after laparoscopic aortobifemoral bypass of 50 patients for aortoiliac occlusive disease, TASC II, type D lesions

\begin{tabular}{|c|c|c|c|c|c|c|}
\hline \multirow[t]{2}{*}{ Time } & \multicolumn{3}{|l|}{ Univariate } & \multicolumn{3}{|l|}{ Multivariate } \\
\hline & Coefficient & $\begin{array}{l}95 \% \text { Confidence } \\
\text { interval }\end{array}$ & $P$-value & Coefficient & $\begin{array}{l}95 \% \text { Confidence } \\
\text { interval }\end{array}$ & $P$-value \\
\hline Time, preop & Ref & & & Ref & & \\
\hline I month & 15.6 & $13.10,18.10$ & 0.001 & 15.5 & $13.00,18.04$ & 0.001 \\
\hline 3 months & 20.3 & $17.10,23.01$ & 0.001 & 20.3 & I7.60, 22.94 & 0.001 \\
\hline 6 months & 19.1 & $16.20,21.90$ & 0.001 & 18.9 & $16.11,21.74$ & $0.00 \mathrm{I}$ \\
\hline Smoking (yes vs no) & 3.5 & $-0.10,7.10$ & 0.056 & 3.8 & $0.63,6.88$ & 0.02 \\
\hline Blood loss (dL) & -0.3 & $-0.53,-0.13$ & 0.001 & -0.3 & $-0.46,-0.09$ & 0.004 \\
\hline Concomitant operation (yes vs no) & -4.1 & $-7.40,-0.70$ & 0.018 & -3.7 & $-6.72,0.69$ & 0.016 \\
\hline ASA (category 3 vs I+2) & -3.6 & $-7.0 \mathrm{I},-0.25$ & 0.035 & & & \\
\hline Length of hospital stay (days) & -0.11 & $-0.32,0.09$ & 0.276 & & & \\
\hline Aorta clamping (minutes) & 0.02 & $-0.05,0.09$ & 0.596 & & & \\
\hline Age (years) & -0.004 & $-0.24,0.23$ & 0.977 & & & \\
\hline Gender (male/female) & 0.7 & $-2.60,3.93$ & 0.689 & & & \\
\hline Operation time (minutes) & 0.002 & $-0.03,0.03$ & 0.903 & & & \\
\hline Prior vascular operation or intervention & 1.8 & $-1.50,5.0 \mid$ & 0.289 & & & \\
\hline
\end{tabular}

Abbreviations: ASA, the American Society of Anesthesiologists category; PCS, Physical Component Score; Ref, reference; SF-36, Short Form-36; TASC, Trans-Atlantic Inter-Society Consensus.

Table 7 Results of the linear mixed-effect regression analysis (univariate and multivariate) of MCS at I, 3 and 6 months after laparoscopic aortobifemoral bypass of 50 patients for aortoiliac occlusive disease, TASC II, type D lesions

\begin{tabular}{llll}
\hline Time & Univariate & & P-value \\
\cline { 2 - 4 } & Coefficient & $\mathbf{9 5 \%}$ Confidence interval & \\
\hline Time, preop & Ref & $-1.25,5.70$ & 0.209 \\
I month & 2.2 & $-0.10,7.44$ & 0.054 \\
3 months & 3.7 & $0.40,8.35$ & 0.03 I \\
6 months & 4.4 & $-1.97,6.84$ & 0.279 \\
Smoking (yes vs no) & 2.4 & $-0.51,0.004$ & 0.054 \\
Blood loss (dL) & -0.3 & $-7.19,1.13$ & 0.153 \\
Concomitant operation (yes vs no) & -3.0 & $-0.50,-0.02$ & 0.034 \\
Length of hospital stay (days) & -0.3 & $-0.02,0.16$ & 0.126 \\
Aorta cross-clamping (minutes) & 0.1 & $-5.25,3.23$ & 0.642 \\
ASA (category 3 vs I+2) & -1.0 & $-0.31,0.26$ & 0.852 \\
Age (years) & -0.03 & $-3.61,4.23$ & 0.877 \\
Gender (male/female) & 0.3 & $-0.06,0.01$ & 0.23 I \\
Operation time (minutes) & -0.02 & $-3.34,4.53$ & 0.768 \\
Prior vascular operation or intervention & 0.6 & . & \\
\hline
\end{tabular}

Abbreviations: ASA, the American Society of Anesthesiologists category; MCS, Mental Component Score; Ref, reference; SF-36, Short Form-36; TASC, Trans-Atlantic Inter-Society Consensus.

HRQL was maintained at 6-month follow-up, which also adds strength to the validity of the HRQL measurements performed in this study with the help of SF-36.

The results of multivariate regression analysis reveal that combining surgical procedures can have a detrimental effect on the postoperative HRQL. Previously, studies have shown increased morbidity and mortality related to concomitant procedures with open or endovascular repair of abdominal aorta. ${ }^{22,23}$ However, in patients with advanced atherosclerotic disease, it is sometimes necessary to perform additional procedures, for example, thromboendarterectomy of the groin arteries or even infrainguinal bypass, to ensure postoperative graft patency. We have previously, in a comparative cohort study design in the same patient population, found a significant relative reduction of the composite events (all-cause mortality, graft occlusion and systemic morbidity) in patients with $\mathrm{LABFB}$ as compared to open $\mathrm{ABFB}$, during a median follow-up time period of 4.12 years. ${ }^{1}$ This may be due to the less-invasive nature of the LABFB procedure. Recently, in a randomized controlled trial of LABFB and OABFB for AIOD, TASC II type D lesions, less postoperative inflammatory response as well as reduced perioperative stress response were found in patients with $\mathrm{LABFB}{ }^{24,25}$ Improvement in the quality of life in the patients found in 
this study after LABFB also adds to the collective evidence of the effectiveness of LABFB.

Positive impact of smoking on the physical domains of SF-36 in this study is an interesting finding. Although we do not have exact explanation for this finding, smoking might have played a role; $74 \%$ of the patients in this study were smokers and might have had a lower preoperative HRQL than nonsmokers, and most of them (80\%) had stopped smoking during the postoperative survey time period. These factors also probably played a role in a comparatively small improvement in $\mathrm{MH}$ scores at 1 and 3-month postoperative survey time points (Figure 1).

The limitation in walking ability has its impact both on physical and emotional health of the patients. ${ }^{10} \mathrm{We}$ also found a significant improvement in the postoperative mental health components of the SF-36 survey, namely, MH, RE and SF. The summary scores, PCS and MCS, showed the same trend in the postoperative improvement in $\mathrm{HRQL}$, as in the case of our findings with the individual domains of SF-36. Our estimations did not show any extreme PCS and MCS scores at any time point. ${ }^{26}$

The limitations of our study are the small sample, noncomparative design, single-center prospective cohort and nonrandomized design. Another limitation is the use of a generic HRQL tool instead of a disease-specific tool. We chose this generic tool for the simple reason that it was both translated into Norwegian language and validated for the Norwegian population. We had no available diseasespecific HRQL tool translated and validated for the patients with peripheral arterial disease at the time this study was conducted. The strengths of the study are the novelty of the study population and the low rates of missing data.

Laparoscopic aortic surgery has been introduced with the aim of reducing the operative burden due to its minimally invasive nature as compared to the open surgery, but at the same time offering the same short- and long-term patency as with OABFB. ${ }^{27}$ Patients' perceived HRQL impact of a disease and its treatment is essential in evaluating the burden of a disease and effectiveness of a treatment. ${ }^{11}$

Patient-reported outcome measures are central in the economic evaluation of new techniques and may help caretakers to make decisions about the choice of treatment. ${ }^{11}$ Our findings should be further examined and verified in the future, preferably in a randomized controlled trial.

\section{Conclusion}

Patients operated with LABFB for the treatment of AIOD, TASC type D lesions have significant improvement in the postoperative self-assessed quality of life.

\section{Acknowledgments}

We are thankful to our colleagues for their continuous support and to the nursing staff at the Department of Vascular Surgery, Oslo University Hospital, Oslo, Norway. We are especially thankful to late Professor Jørgen Junkichi Jørgensen for his support during the conduct of this study and in the data collection for the study, and for the establishment of laparoscopic aortic surgery in our department.

\section{Authors' contributions}

SSHK contributed to conception and design; SSHK and RSF analyzed and interpreted data, and performed statistical analysis; SSHK held the overall responsibility for this study. All authors contributed toward data analysis, drafting and revising the paper and agree to be accountable for all aspects of the work.

\section{Disclosure}

The authors report no conflicts of interest in this work.

\section{References}

1. Kazmi SSH, Jørgensen JJ, Sundhagen JO, et al. A comparative cohort study of totally laparoscopic and open aortobifemoral bypass for the treatment of advanced atherosclerosis. Vasc Health and Risk Manag. 2015;11:541-547.

2. Norgren L, Hiatt WR, Dormandy JA, Nehler MR, Harris KA, Fowkes FG. Inter-society consensus for the management of peripheral arterial disease (TASC II). J Vasc Surg. 2007;45 (Suppl S):S5-S67.

3. Klimach SG, Gollop ND, Ellis J, Cathcart P. How does subintimal angioplasty compare to transluminal angioplasty for the treatment of femoral occlusive disease? Int J Surg. 2014;12(4):361-364.

4. Coggia M, Javerliat I, Di Centa I, et al. Total laparoscopic bypass for aortoiliac occlusive lesions: 93-case experience. J Vasc Surg. 2004;40(5): 899-906.

5. Tiek J, Remy P, Sabbe T, et al. Laparoscopic versus open approach for aortobifemoral bypass for severe aorto-iliac occlusive disease - a multicentre randomised controlled trial. Eur J Vasc Endovasc Surg. 2012;43(6):711-715.

6. de Vries SO, Hunink MG. Results of aortic bifurcation grafts for aortoiliac occlusive disease: a meta-analysis. J Vasc Surg. 1997;26(4): 558-569.

7. Bruls S, Quaniers J, Tromme P, Lavigne JP, Van Damme H, Defraigne JO. Comparison of laparoscopic and open aortobifemoral bypass in the treatment of aortoiliac disease. Results of a contemporary series (2003-2009). Acta Chir Belg. 2012;112(1):51-58.

8. Cassar K, Bachoo P, Brittenden J. The ffect of peripheral percutaneous transluminal angioplasty on the quality of life in patients with intermittent claudication. Eur J Vasc Endovasc Surg. 2002;26(2):130-136.

9. Forbes JF, Adam DJ, Bell J, et al. Bypass versus Angioplasty in Severe Ischaemia of the Leg (BASIL) trial: health-related quality of life outcomes, resource utilization, and cost-effectiveness analysis. JVasc Surg. 2010;51 (Suppl 5):43S-51S.

10. Spronk S, Bosch JL, Veen HF, et al. Intermittent claudication: functional capacity and quality of life after exercise training or percutaneous transluminal angioplasty-systemic review. Radiology. 2005;235:833-842.

11. Caitlin W Hicks, YW Lum. Patient-reported outcome measures in vascular surgery. Semin Vasc Surg. 2015;28(2):122-133.

12. Cau J, Ricco JB, Corpataux JM. Laparoscopic aortic surgery: techniques and results. J Vasc Surg. 2008;48 (Suppl 6):37S-44S; discussion 5S.

13. Ware JE, Sherbourne CD. The MOS 36-item Short-Form Health Survay (SF-36): conceptual framework and item selection. Med Care. 1992;30(6):473-483. 
14. Rutherford RB, Baker JD, Ernst C, et al. Recommended standards for reports dealing with lower extremity ischemia: revised version. J Vasc Surg. 1997;26(3):517-538.

15. Mays RJ, Casserly IP, Kohrt WM, et al. Assessment of functional status and quality of life in claudication. J Vasc Surg. 2001;53(5): 1410-1421.

16. Hicken GJ, Lossing AG, Ameli F. Assessment of generic health-related quality of life in patients with intermittent claudication. Eur J Vasc Endovasc Surg. 2000;20(4):336-341.

17. Currie IC, Wilson YG, Baird RN, Lamont PM. Treatment of intermittent claudication: the impact on the quality of life. Eur JVasc Endovasc Surg. 1995;10(3):356-361.

18. Ware JE, Kosinski M. SF-36 Physical and Mental Health Summary Scales: A Manual for Users of Version 1. 2nd ed. Lincoln, RI: QualityMetric, Inc.; 2001

19. Loge JH, Kaasa S. Short form 36 (SF-36) health survey: normative data from the general Norwegian population. Scand J Soc Med. 1998; 26(4):250-258

20. Wolfe F, Kong SX, Watson DJ. Gastrointestinal symptoms and health related quality of life in patients with arthritis. J Rheumatol. 2000; 27(6):1373-1378.
21. Campbell NC, Thain J, Deans HG, Ritchie LD, Rawles JM, Squair JL. Secondary prevention clinics for coronary heart diasease: randomized trial of effect on health. BMJ. 1998;316(7142):1434-1437.

22. Ultee KHJ, Soden PA, Zettervall SL, et al. The perioperative effect of concomitant procedures during open infrarenal abdominal aortic aneurysm repair. J Vasc Surg. 2016;64(4):934-940.e1.

23. Ultee KHJ, Zettervall SL, Soden PA, et al. The impact of concomitant procedures during endovascular abdominal aortic aneurysm repair on perioperative outcomes. JVasc Surg. 2016;63(6):1411-1419.e2.

24. Krog AH, Sahba M, Pettersen EM, et al. Comparison of the acute-phase response after laparoscopic versus open aortobifemoral bypass surgery: a substudy of a randomized controlled trial. Vasc Health Risk Manag. 2016;12:371-378.

25. Krog AH, Thorsby PM, Sahba M, et al. Perioperative humoral stress response to laparoscopic versus open aortobifemoral bypass surgery. Scan J Clin Lab Invest. 2017;9:1-10.

26. Ware JE, Kosinski M. Interpreting SF-36 summary health measures: a response. Qual Life Res. 2001;10(5):405-413; discussion 415-420.

27. Dion YM, Griselli F, Douville Y, Langis P. Early and mid-term results of totally laparoscopic surgery for aortoiliac disease: lessons learned. Surg Laparosc Endosc Percutan Tech. 2004;14(6):328-334.
Vascular Health and Risk Management

\section{Publish your work in this journal}

Vascular Health and Risk Management is an international, peerreviewed journal of therapeutics and risk management, focusing on concise rapid reporting of clinical studies on the processes involved in the maintenance of vascular health; the monitoring, prevention and treatment of vascular disease and its sequelae; and the involvement of
Dovepress

metabolic disorders, particularly diabetes. This journal is indexed on PubMed Central and MedLine. The manuscript management system is completely online and includes a very quick and fair peer-review system, which is all easy to use. Visit http://www.dovepress.com/ testimonials.php to read real quotes from published authors. 